\title{
Characteristics of Air-Sea Fluxes Based on In Situ Observations from a Platform in the Bohai Gulf during Early Mid-August 2011
}

\author{
Bingui Wu, ${ }^{1}$ Yiyang Xie, ${ }^{1}$ Yi Lin, ${ }^{1}$ Xinxin Ye, ${ }^{2}$ Jing Chen, ${ }^{1}$ Xiaobing Qiu, ${ }^{1}$ and Yanan Wang ${ }^{1}$ \\ ${ }^{1}$ Tianjin Municipal Meteorological Bureau, Tianjin 300074, China \\ ${ }^{2}$ Laboratory for Climate and Ocean-Atmosphere Studies, Department of Atmospheric and Oceanic Sciences, \\ School of Physics, Peking University, Beijing 100871, China
}

Correspondence should be addressed to Yiyang Xie; tjqxjs@126.com

Received 22 February 2013; Revised 2 May 2013; Accepted 10 May 2013

Academic Editor: Bin Liu

Copyright (C) 2013 Bingui Wu et al. This is an open access article distributed under the Creative Commons Attribution License, which permits unrestricted use, distribution, and reproduction in any medium, provided the original work is properly cited.

\begin{abstract}
An eddy covariance system and other atmospheric and oceanic parameters were measured simultaneously from a fixed Platform-A in the Bohai Gulf during early mid-August 2011. One of the main goals of the comprehensive observation was to reveal the basic meteorological and hydrological characteristics of the Bohai Gulf. The results indicated that the diurnal characteristic curve for the air temperature (AT) was steeply unimodal, while the curve of the SST was a bimodal valley type and mainly influenced by tides with its valley value corresponding to the high water level during the observation period. Southeasterly winds dominated and the wind speed was generally lower than $8 \mathrm{~m} / \mathrm{s}$, and the atmospheric stability over the Bohai Gulf was generally unstable. The wave strength levels were generally below level 3 , with a greater number of swell waves than wind waves. The latter were usually associated with more momentum transport, a larger difference between AT and SST, and less heat transport. During the observational period, the mean momentum, sensible, and latent heat turbulent fluxes were $0.21,21.6$, and $27.8 \mathrm{~W} / \mathrm{m}^{2}$, respectively. The ratio of the mean latent and sensible turbulent fluxes was about 1.3 and much lower than that in the South China Sea during the summer.
\end{abstract}

\section{Introduction}

The exchanges of heat, mass, and momentum between the atmosphere and the ocean are very influential on the structure of the marine boundary layer. They also influence the atmosphere both locally and globally, as well as ocean circulation. However, sensible heat and water vapor fluxes have depend on many parameters which are still considered to be unclear [1-3]. Such as whitecap element, which begin to appear on the ocean surface at wind speed as low as $3 \mathrm{~m} / \mathrm{s}$ and cover a significant fraction $(>1 \%)$ of the ocean surface at wind speed of about $10 \mathrm{~m} / \mathrm{s}$ [4], increasing at a rate approximately proportional to the cube of the surface layer wind speed [5]. Again such as breaking waves, which alter the surface roughness characteristics of the ocean and produce sea spray droplets and affect the air-sea exchange process [6], and so on. The air-sea energy and mass exchange process becomes more complicated [3,7]. In spite of a large amount of experimental data its uncertainty is unacceptably high for calculations of climatological heat transports. Since a comprehensive understanding of the mechanics of air-sea interaction is fundamentally important for the study of ocean circulation models, ocean-atmosphere coupled models, and the energy and water cycle, in order to estimate the air-sea fluxes, air-sea exchange observation had been treated as the main content in Tropical Ocean and Global Atmosphere, Coupled Ocean-Atmosphere Response Experiment (TOGA COARE) [8]. It has helped to improve our understanding of the characteristics of air-sea exchange in many ocean areas including the warm pool in the western Pacific Ocean, the Kuroshio region, and the South China Sea monsoon region $[9,10]$. Along Chinese coastal waters, most studies on airsea fluxes have been focused on the South China Sea [7]. The characteristics of heat fluxes before and after the start of the South China Sea summer monsoon have been identified. The equations for bulk transport coefficients and the bulk transport improved method in the region of the South China Sea have been also uncovered [11]. These jobs have given us a better understanding of the air-sea heat fluxes during the eruption period of the South China Sea summer monsoon. 


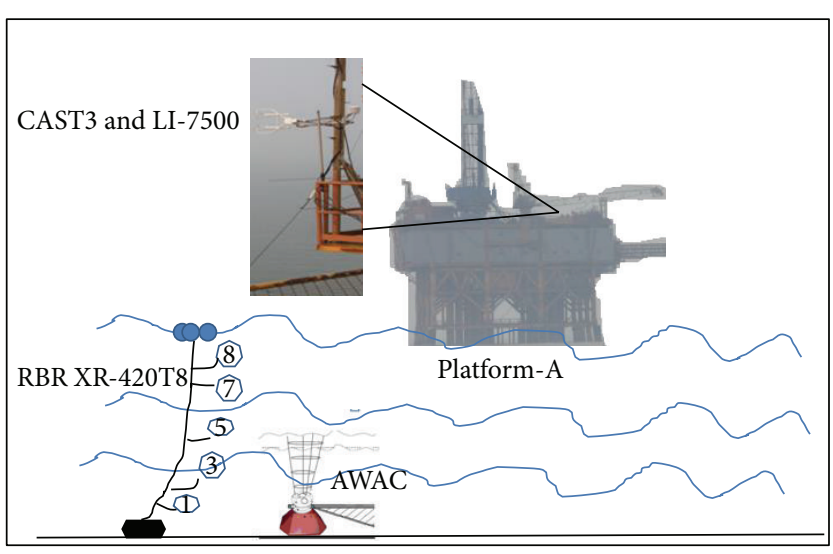

(a)

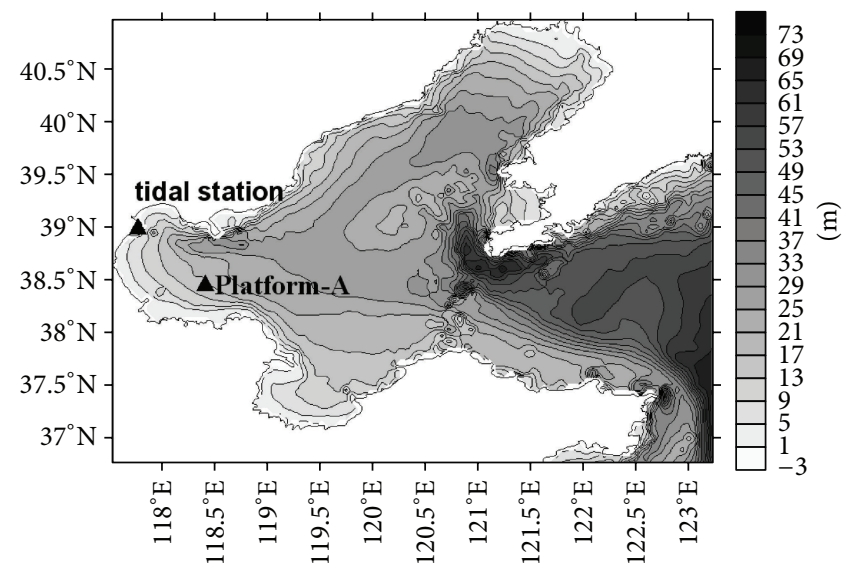

(b)

Figure 1: Platform-A in the Bohai Gulf and related observation instruments (a). Tide gauge station and Platform-A and water level (b).

The variations in heat fluxes at different seasons, latitudes, and coastal topographies over Chinese coastal waters have been noted by Yan et al. [12]. The heat, momentum, and water vapor fluxes under different weather conditions over the sea surface have been calculated by using the observational dataset obtained over the Xi'sha marine region in the South China Sea. Overall, research on air-sea fluxes over the South China Sea has focused on the air-sea fluxes before and after the start of the South China Sea summer monsoon. There has also been research into variations in radiation and turbulence during different weather conditions, the diurnal variation of air-sea fluxes, the bulk transport coefficients, and the influences of flux variations on the lower atmosphere and upper ocean mixing layer. According to Vickers and Mahrt [13], the momentum and sensible heat fluxes over middlelatitude coastal waters are lower than those over the open sea surfaces, and latent heat fluxes are even lower, often by 20\%-50\%. Compared to the South China Sea, the study of the Bohai Gulf has been fairly limited so far. Furthermore, the knowledge acquired about the South China Sea may not be valid for the Bohai Gulf. Therefore, it is necessary to do further research on air-sea interactions over the Bohai Gulf.

An observation campaign was conducted from the end of July 2011 on the Platform-A $\left(38^{\circ} 27^{\prime} \mathrm{N}, 118^{\circ} 25^{\prime} \mathrm{E}\right)$ in the Bohai Gulf. In addition to conventional meteorological observations like air temperature (AT), wind, humidity, precipitation, cloud cover, and visibility, additional observations were included. The sea surface temperature (SST), ocean current profile, AT changes, specific humidity, and three-dimensional wind components were carried out. Marine observations are limited by many factors, such as damage done to the floating observation instrumentation by currents and waves. Since the data from early mid-August 2011 was comparably complete, data of this period were chosen for analysis for the sake of understanding of atmospheric-ocean interactions in middlelatitude continental seas. It would be beneficial to lay the foundation of further getting the quantitative description of the exchanges of heat, mass, and momentum between the atmosphere and the ocean. We present results from the comprehensive observation and show evidence of low correlation between the mean momentum flux and the wind speed. And we find that the daily variation of SST is Mtype and mainly influenced by an irregular semidiurnal tide with the minimum SST corresponding to the high water level during the observation period. We also find that the sensible and latent heat fluxes have the same comparable importance in the Bohai Gulf.

\section{Data and Methods}

2.1. Marine Observation Platform-A and Instrumentation. The air-sea fluxes over the ocean surface are generally observed by stand or mobile platforms settled in the sea $[2,14]$. The observation platform used in our experiment was the Chengbei Platform-A (Station Identity no. 54646) located in the Bohai Gulf $\left(38^{\circ} 27^{\prime} \mathrm{N}, 118^{\circ} 25^{\prime} \mathrm{E}\right)$ where water level is about $19 \mathrm{~m}$ (Figure 1(b)). It is a fundamental meteorological observation station managed by the China Meteorological Administration. The platform is located at $70 \mathrm{~km}$ off the west coast and $40 \mathrm{~km}$ off the south coast of the Bohai Gulf. It is an excellent platform for conducting marine observations and $30.3 \mathrm{~m}$ height above mean sea level. The barometer and anemometer are located $2 \mathrm{~m}$ and $6.5 \mathrm{~m}$ above the Platform-A, respectively. In 2005, automatic observation instruments replaced the artificial observation techniques which dated back to January 1988, with observers monitoring the instrument operations. The observation data has been kept consecutively to this day.

An eddy covariance system was used to acquire supporting meteorological and boundary layer flux data. The eddy covariance system included a three-axis anemometer/thermometer (CAMPBELL CSAT3, USA) and an openpath infrared hygrometer $\mathrm{CO}_{2} / \mathrm{H}_{2} \mathrm{O}$ sensor (Licor-7500). The eddy covariance system was installed on an abandoned mast at the height of $5 \mathrm{~m}$ above the Platform-A. The semigirders were set up the north-south direction and the instruments faced the north. The sampling frequency was $10 \mathrm{~Hz}$. The sections of wave and current speed were measured with an Acoustic Wave and Current (AWAC) from the Nortek Company based in Norway. In addition to having 
TABLE 1: List of instruments used during the intensive observations on air-sea fluxes.

\begin{tabular}{|c|c|c|c|}
\hline Instrument & Precision & Temporal resolution/frequency & Sample layer \\
\hline $\begin{array}{l}\text { Ultrasonic anemometer (CSAT3; } \\
\text { Campbell, USA) }\end{array}$ & $\begin{array}{l}u, v, 1 \mathrm{~mm} / \mathrm{s} ; w, 0.5 \mathrm{~mm} / \mathrm{s} \\
\text { sound velocity, } 1 \mathrm{~mm} / \mathrm{s}\end{array}$ & $10 \mathrm{~Hz}$ & $5 \mathrm{~m}$ above the Platform-A \\
\hline $\begin{array}{l}\mathrm{CO}_{2} / \mathrm{H}_{2} \mathrm{O} \text { analyzer (Li7500; LiCor, } \\
\text { USA) }\end{array}$ & $0.1 \mu \mathrm{mol} / \mathrm{mol}$ & $10 \mathrm{~Hz}$ & $5 \mathrm{~m}$ above the Platform-A \\
\hline $\begin{array}{l}\text { Thermistor chain (XR-420 T8; RBR, } \\
\text { Canada) }\end{array}$ & $0.005^{\circ} \mathrm{C}$ & $20 \min$ & $\begin{array}{l}\text { Undersea } 1,3,5,7.5,10,12.5 \text {, } \\
15 \mathrm{~m} \text { and the seabed }\end{array}$ \\
\hline Acoustic wave and current (AWAC) & $\begin{array}{c}\text { Current speed, } 1 \% \pm 0.5 \mathrm{~cm} / \mathrm{s} \\
\text { wave height, }<1 \% / \mathrm{cm} \\
\text { wave direction, } 0.1^{\circ} / 2^{\circ}\end{array}$ & $0.05 \mathrm{~Hz}$ & $\begin{array}{l}\text { Surface wave height, vertical } \\
\text { section current speed }\end{array}$ \\
\hline
\end{tabular}

the traditional features of an Acoustic Doppler Current Profiler (ADCP) used to measure the waves and current speeds, it can also detect wave height with Acoustic Surface Tracking (AST). The XR-420 T8 (RBR Company) was used to detect the sea water temperature section and vertical gradients. It was placed eight meters west of the observation platform and included eight temperature sensors equipped on the vertical chain (Figure 1(a)). Due to the loss of a bearing rope (and abrasion on the main one), the electric cable became overloaded, which caused the temperature section sensors to break down on August 17, 2011. Therefore, data from the August 3rd to 16th was selected for analysis. Tide gauge station used was located at the western coast of the Bohai Gulf $\left(38^{\circ} 59^{\prime} \mathrm{N}, 117^{\circ} 46^{\prime} \mathrm{E}\right)$. It is a facility of flood control departments of Municipal government and about $91 \mathrm{~km}$ northwest of Platform-A (Figure 1(b)).

During the observation period, the platform was out of the monitoring of observers from 04:00 Beijing standard time (BJT, the same later) on August 7th to 09:00 BJT on August 9th because of typhoon, "Meihua," which caused missing data for August 7th and August 8th, including present weather, visibility, total amount of clouds, amount of low clouds, and cloud classifications. They were artificially and conventionally observed at 08:00, 14:00, and 20:00 BJT. In addition, due to a power failure from 01:32 to 12:21 BJT on August 8th, the data detected per minute with the automatic meteorological weather station is missing, including atmospheric pressure, air temperature, relative humidity, wind direction, and wind speed. The ultrasonic anemometer and $\mathrm{CO}_{2} / \mathrm{H}_{2} \mathrm{O}$ infrared analyzer also lost power. In terms of the hydrological data, the data of wave height and current speed from 19:45 to 22:20 BJT on August 7th is missing due to the power failure. The parameters of the instruments are listed in Table 1.

2.2. Data Processing. The TK2 Software developed by Bayreuth University in Germany was used for processing the high-frequency data to calculate heat and momentum fluxes $[15,16]$. The turbulent fluxes of momentum, heat, and moisture were calculated over $30 \mathrm{~min}$ averages. The main formulas used are listed as follows:

friction velocity:

$$
u_{*}=\left({\overline{u^{\prime} w^{\prime}}}^{2}+{\overline{v^{\prime} w^{\prime}}}^{2}\right)^{1 / 4}
$$

Monin-Obukhov Length:

$$
L=\frac{-u_{*}^{3}}{\left(k(g / T) \overline{w^{\prime} T_{S}^{\prime}}\right)},
$$

momentum flux:

$$
\tau=-\rho u_{*}^{2}
$$

sensible heat flux:

$$
Q_{h}=\rho C_{p d}(1+0.84 q) \overline{w^{\prime} \theta^{\prime}}
$$

latent heat flux:

$$
Q_{e}=\rho L_{v} \overline{w^{\prime} q^{\prime}}
$$

In the previous equations, $u, v$, and $w$ are the horizontal and vertical component of turbulent velocity vector. $T_{s}$ is virtual temperature and $\theta$ is the potential temperature. $q$ is specific humidity measured by the $\mathrm{CO}_{2} / \mathrm{H}_{2} \mathrm{O}$ analyzer. The primes indicate turbulent quantities taken as deviations from the mean and the overbars represent ensemble averages. Here, $\rho$ stands for air density, $k$ for the Von-Karman constant ( 0.4 generally), $g$ for acceleration due to gravity $\left(9.8 \mathrm{~m} / \mathrm{s}^{2}\right.$ generally), $C_{p d}$ for the specific heat of dry air at constant pressure, $L_{v}$ for latent heat for evaporation, and $z$ for the observation height.

Considering the observation instruments (the barometer, anemometer, and the eddy covariance system) that are located $2 \mathrm{~m}$ to $5 \mathrm{~m}$ over the Platform, heat, moisture, and momentum fluxes discussed in the paper are almost still constant compared to the height $10 \mathrm{~m}$. So attitude difference correction is not necessary. Strict data quality control methods were applied during the data processing with the TK2 software. Except for rejecting those data with quality labels greater than 7 marked by the TK2, some abnormal data for periods with rain, thunder, and weak winds was also rejected for the sake of data quality control. 


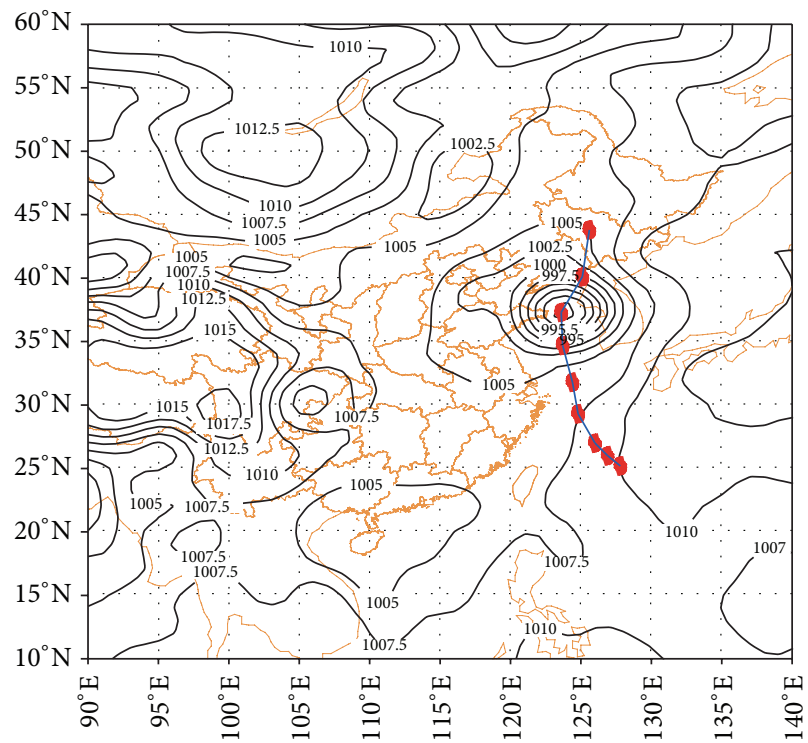

(a)

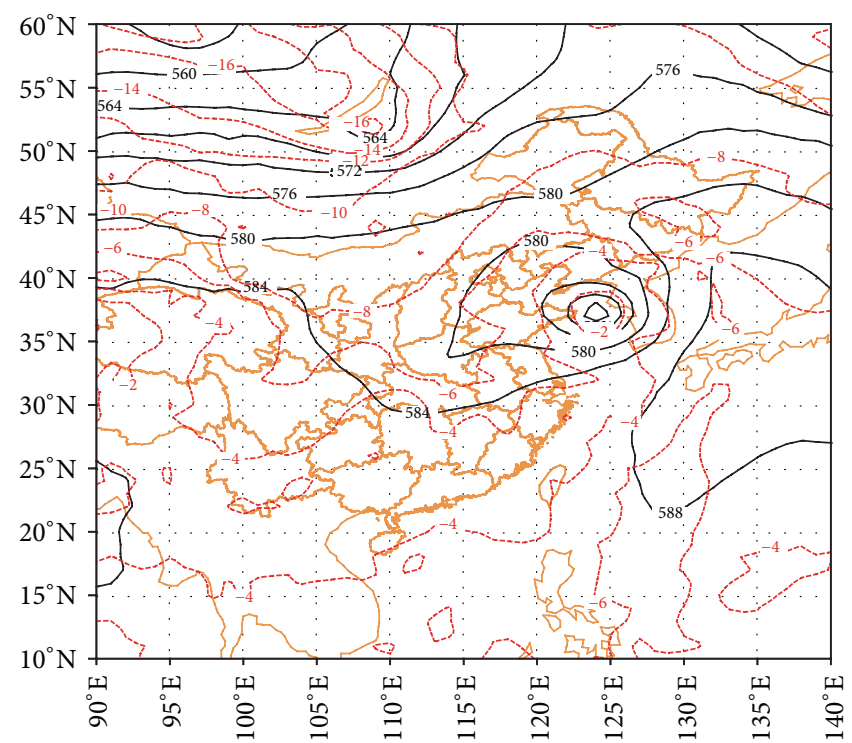

(b)

Figure 2: Surface weather map at 08BJT on August 8th along with typhoon mark symbol every 12 hours on the drawing from south at 08BJT on August 5th to north at 08BJT on August 9th of 2011 (a) and $500 \mathrm{hPa}$ temperature (red line) and geopotential height (black line) at 08BJT on August 8th of 2011 (b).

\section{Results and Discussion}

3.1. Main Synoptic Processes. In early August, Northern China endures its main flood season. The region is dominantly controlled by the subtropical anticyclone system and the "westerlies." The tropical cyclones proceeding northwards bring frequent precipitation. During the observation period, the subtropical anticyclone maintained its eastern direction to the Sea of Japan. From August 3rd to 8th, the severe typhoon (No. 201109, "Meihua") passed through the East China Sea and headed into the northern Yellow Sea. According to the synoptic weather map, it was clear at the observation site caused by the continental high pressure system from August 3rd to 5th with $500 \mathrm{hPa}$ isobaric surface. On August 6th, heavy rain fell over the Bohai Gulf in relation to the east-moving upper air trough. After passing the Bohai Gulf, typhoon "Meihua" made landfall on the western coast of North Korea and turned into a low pressure system (Figure 2). Although typhoon system caused surface pressure descending, it did not lead to any precipitation near the observation site. However, the weakened cyclone did make it cloudy. The weather was then clear, and it was controlled once again by the continental anticyclone form on August 9th10th. There were showers on August 11th when a west-moving cyclone formed near the Yellow River (referred to as Yellow River cyclone) passed by. On August 12th-13th, it was cloudy weather again due to surface low pressure system influenced by Yellow River cyclone passing by. It turned clear on the 14th and conditions were once again influenced by the continental anticyclone. On the 15th, steady western flows occurred in the upper air and, because of the vortex in the lower atmosphere and the inversed trough at the surface, a short-time thunderstorm with strong winds occurred (Figure 3 ). In conjunction with the variations in wind direction, every precipitation event occurred before the transition of a southeasterly wind into a northeasterly wind. Here, the northeasterly wind was always maintained for a short time. The phenomena were in accordance with the generally held rule in which precipitation always occurs when the summer monsoon system retreats and northern high-pressure systems strengthen during early mid-August.

3.2. Ocean Surface Humidity and Wind Speed. During earlymid August, the relative humidity (RH) at the ocean surface was generally above $60 \%$ without any significant interdiurnal variations (Figure $3(\mathrm{a})$ ). The $\mathrm{RH}$ reached about $82 \%$, when northeasterly or southeasterly winds dominated, and $76 \%$ during southwesterly winds. The atmosphere was comparably dry when the northwesterly winds prevailed, and here the $\mathrm{RH}$ was about $73 \%$.

In the summer, the winds are moderate over the Bohai Gulf. They generally held between weak and medium strength. Winds with speeds below $8 \mathrm{~m} / \mathrm{s}$ accounted for $97.6 \%$ of conditions. Here, winds with speeds below $3 \mathrm{~m} / \mathrm{s}$ accounted for $39.3 \%, 3-6 \mathrm{~m} / \mathrm{s}$ for $51 \%$, and $6-8 \mathrm{~m} / \mathrm{s}$ for $7.3 \%$, and the remaining $2.4 \%$ were between 8 and $14 \mathrm{~m} / \mathrm{s}$. The latter speeds generally occurred during the thunderstorm periods (Figure 3(b)). During the three periods of precipitation, the RH reached nearly $85 \%$, and southeasterly winds with speeds of $3 \mathrm{~m} / \mathrm{s}$ prevailed. During the strong convection period on August 15th, the wind speed was greater than $6 \mathrm{~m} / \mathrm{s}$ several times (Figure 3(b)).

3.3. Air Temperature, Ocean Surface Temperature, and Their Discrepancies. The air temperature (AT) was primarily affected by the amount of clouds, precipitation, and the invasion of warm or cold airflows (Figure 4). 


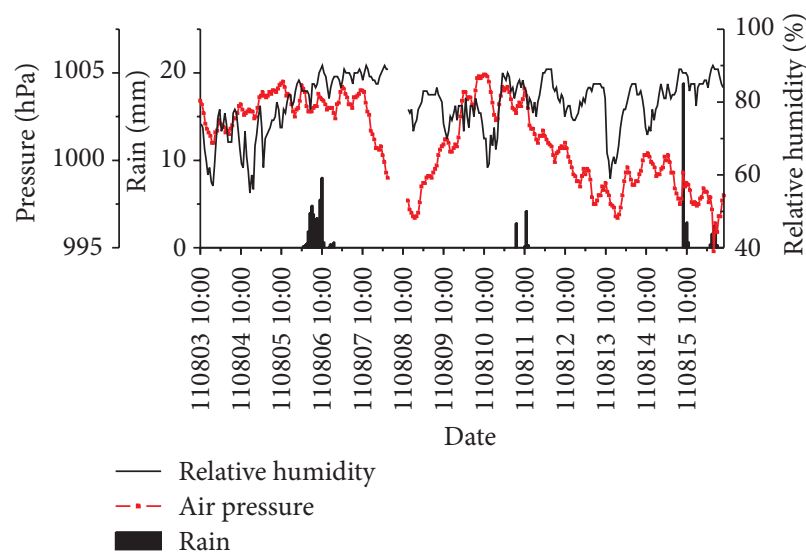

(a)

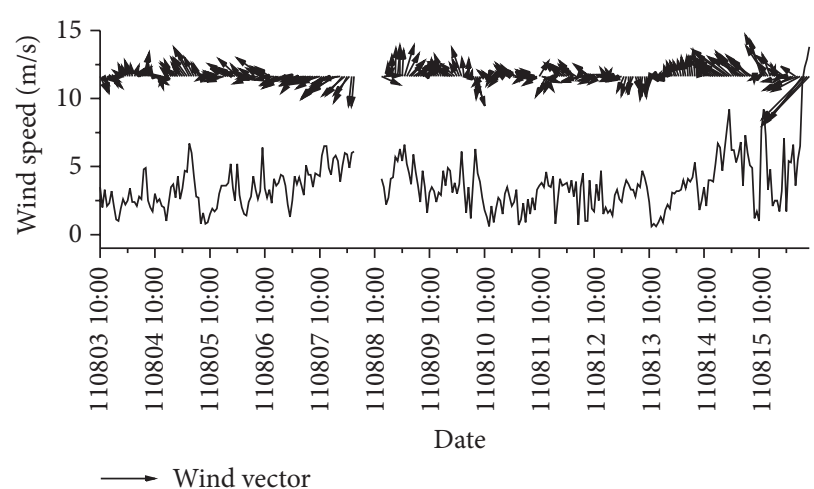

(b)

FIGURE 3: Inter-diurnal variation of meteorological elements ((a) relative humidity, precipitation, surface pressure; (b) wind speed and wind direction).

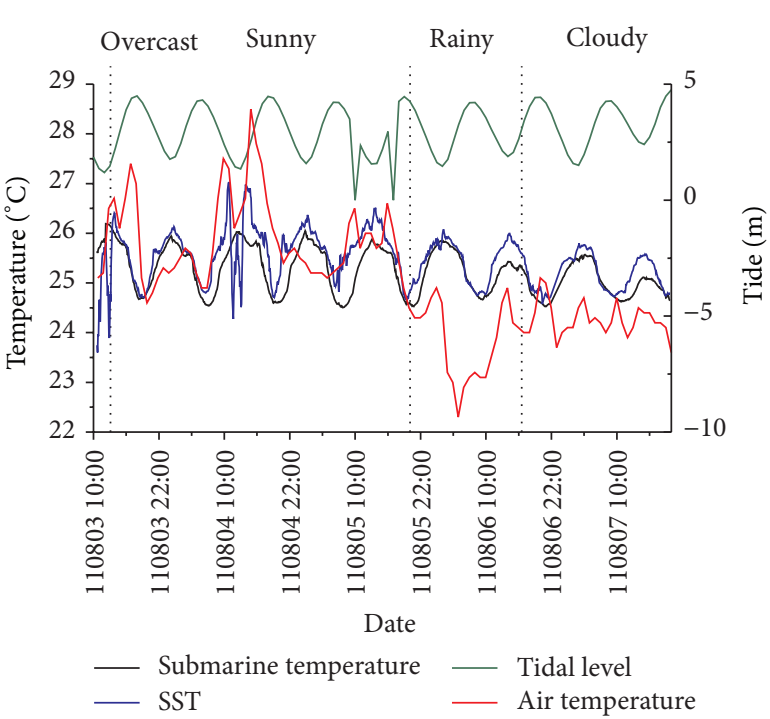

(a)

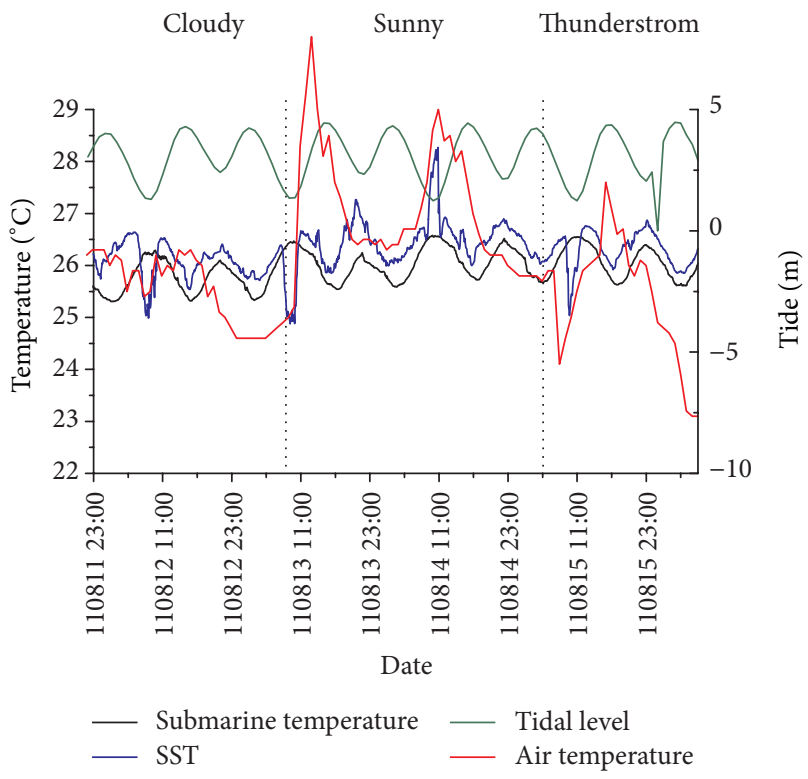

(b)

FIGURE 4: Time series for air temperature, SST, and tide level.

During clear weather, the diurnal variation of AT was large, reaching the maximum average of $26.2^{\circ} \mathrm{C}$. It generally occurred around 15:00 BJT. During cloudy weather or during precipitation, the incoming solar radiation was decreased. Here, the AT decreased remarkably, especially during precipitation. The mean $\mathrm{AT}$ was about $24.3^{\circ} \mathrm{C}$. It was $1.9^{\circ} \mathrm{C}$ lower than that during the clear conditions. Synoptic weather backgrounds can be representative with wind directions. Here, among the northern winds presented cold airflows from the systems to the north, with the average temperature of $25.5^{\circ} \mathrm{C}$. Meanwhile, southern winds were created by the warm advection in relation to the southern systems, and the average temperature here was $26.7^{\circ} \mathrm{C}$.
During the period of observation, the mean sea surface temperature (SST) was $25.9^{\circ} \mathrm{C}$, and the mean bottom water temperature was $25.6^{\circ} \mathrm{C}$. The variation tendencies in temperature at several depths were generally similar. The difference between the surface and bottom water temperatures averaged only $0.3^{\circ} \mathrm{C}$, which indicated very strong vertical mixing of sea water and the removal of the thermocline. Although the variation tendency of SST was almost the same as the bottom water temperature, the former varied with more fluctuations and was similar to the variations in the AT. Sometimes, the SST varied in accordance with the AT, leading to large difference between the SST and bottom water temperature. Here, there was the maximum of $3.3^{\circ} \mathrm{C}$ and the minimum of $-3.9^{\circ} \mathrm{C}$. This indicated the fact that surface water is less 
resistant to changes in meteorological conditions such as radiation and winds.

The sea water temperature showed notable diurnal variation as well. In contrast to the unimodal-type curve of AT, the SST varied as an M-type curve. Here, two SST peaks appeared in the afternoon and near the midnight. The peaks were higher during the daytime than at nighttime, representing the heating effect of insolation. In comparison with the hourly recorded tide level from the Hydrometric Station, it was shown that an inverse correlation existed between the tide level and the sea water temperature (Figure 4). Since strong tidal currents occur in the Bohai Gulf (mainly an irregular semidiurnal tide), sea water temperature was closely related to tidal current activity. It is consistent with the observational results shown by Tang et al. [17].

When the observation experiment was conducted during early-mid August, the difference between SST and AT was obvious. On clear afternoons, the maximum AT was greater than SST by $1.5^{\circ} \mathrm{C}$. During other periods, the AT was generally less than SST by about $0.5^{\circ} \mathrm{C}$. Overall, AT over the Bohai Gulf exceeded SST during $62.9 \%$ of the total period. Furthermore, $63.3 \%$ of the data showed the air-sea temperature difference within $1^{\circ} \mathrm{C}$. The results were different those that obtained in the South China Sea, where the daily SST average was almost always greater than the AT [12]. The one of possible reasons about the difference is because the ocean current temperature decreases with the latitude zone from the south to the north, while air temperature at both latitude zones is comparative in early-mid August. However, regardless of the weather conditions, the AT varied more evidently than the SST. It has the similar characteristic to the others as a semienclosed shallow sea, whose SST and AT are determined by the physical properties of both the sea water and the air.

3.4. Marine Boundary Layer Stratification. The stability of the lower atmosphere is an important factor for determining turbulence strength and diffusion conditions. It plays a primary role in the study of turbulence structure and for the estimation of surface fluxes.

Several common methods used to determine atmospheric stability have been previously pointed out. For instance, the temperature difference method [18] and the MoninObukhov (M-O) length method [19] are commonly used during observation experiments. Different criteria can draw different conclusions. When analyzing the Bohai Gulf, if we assumed positive air-sea temperature difference as an indicator of unstable marine boundary layer (MBL), then $62.9 \%$ unstable conditions would be yielded during the experiment period. Meanwhile, with $\mathrm{M}-\mathrm{O}$ length method as a criterion, unstable conditions accounted for $70.2 \%$. The judgments acquired by using two kinds of methods were often inconsistent. So the way to choose a reasonable indication for atmospheric stability is imperative.

In order to determine which indicator was better, two days of August 4th (clear) and August 12th (cloudy) with typical weather cases were selected. From 08:00 BJT to 08:00 BJT (August 4th-5th), it was clear with some dense cirrus clouds. From 08:00 BJT to 08:00 BJT (August 12th-13th), the sky contained $80 \%$ low-middle clouds. Figure 5 demonstrates

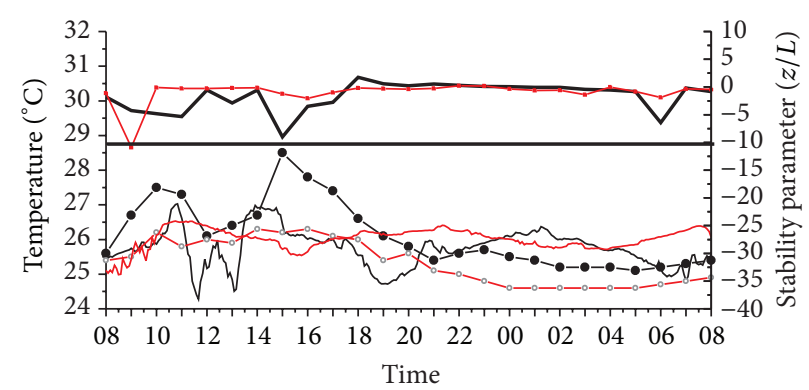

$$
\begin{array}{ll}
- \text { Sunny } & - \text { Sunny SST } \\
-\bullet-\text { Cloudy } & -\bullet \text { Cloudy Tair } \\
-\bullet-\text { Sunny Tair } & - \text { Cloudy SST }
\end{array}
$$

FIGURE 5: Air temperature and sea surface temperature on clear and cloudy days. The thin lines denote $\mathrm{z} / \mathrm{L}$ on clear day (in black) and cloudy day (in red).

the temporal variation of the AT, SST, and stability parameter $\mathrm{z} / \mathrm{L}$. It can be seen that, on the clear day, the value of $\mathrm{z} / \mathrm{L}$ was negative after sunrise, denoting unstable stratification. Meanwhile, after sunset, the MBL was neutral with $\mathrm{z} / \mathrm{L}$ near zero. On the cloudy day, the values of $\mathrm{z} / \mathrm{L}$ were approaching zero almost the entire day, which indicated the stratification to be neutral. Nevertheless, considering SST minus AT, when the AT increased during the day and suppressed the SST, the MBL was supposed to be stable. The opposite was considered true when the AT decreased at night. The differences between the two methods are shown clearly by the two selected cases.

Atmospheric stability is related to discrepancies in density, temperature, and the velocity of a certain air parcel within the surrounding air (especially the vertical gradient). The vertical motion of an air parcel is caused thermodynamically through buoyancy or mechanical force by windstress. The criterion of SST minus AT considers only the thermodynamic factor, leaving out the influences of ocean surface conditions and wind stress. Therefore, it is considered to be comparably less reliable than the $\mathrm{M}-\mathrm{O}$ length criterion. The $\mathrm{M}-\mathrm{O}$ length takes both thermal and mechanical factors into account at the same time. In this way, the M-O length is a better indicator of atmospheric stability.

From this point on, the dimensionless form of $\mathrm{M}-\mathrm{O}$ length (i.e., $\mathrm{z} / \mathrm{L}$ ) was used as the criterion for the stability of the atmosphere over the Bohai Gulf. The negative $\mathrm{z} / \mathrm{L}$ values denoted unstable stratifications, which accounted for $70.2 \%$ of the overall conditions. The positive values for stable conditions accounted for $29.8 \%$. Here, if we take $\mathrm{z} / \mathrm{L}$ within -0.1 to 0.1 as the neutral condition, $25.6 \%$ of all data was satisfied. The results showed that the Bohai Gulf presented unstable stratification in the lower atmosphere the majority of the time during early-mid August. It was different from the conditions over the South China Sea, where there was lower atmospheric instability almost all of the time [20].

3.5. Wave Shapes and Wave-Coherent Dynamic and Thermodynamic Features. Over the last decade it has become apparent that surface wave process can play an important role in the kinematics and dynamics of the boundary layers 
TABLE 2: Wave-coherent features of wind, air temperature, and SST.

\begin{tabular}{|c|c|c|c|c|c|}
\hline \multirow[b]{2}{*}{ Category } & \multicolumn{2}{|c|}{ Grouped by wave shape } & \multicolumn{3}{|c|}{ Grouped by wave height } \\
\hline & Wind wave & Swell wave & $\begin{array}{c}\text { Level-2 } \\
(0.1-0.4 \mathrm{~m})\end{array}$ & $\begin{array}{c}\text { Level-3 } \\
(0.5-1.2 \mathrm{~m})\end{array}$ & $\begin{array}{c}\text { Level-4 } \\
(1.3-2.4 \mathrm{~m})\end{array}$ \\
\hline Average wind speed $(\mathrm{m} / \mathrm{s})$ & 3.6 & 1.5 & 1.8 & 3.0 & 9.6 \\
\hline Maximum wind speed $(\mathrm{m} / \mathrm{s})$ & 13.8 & 4.1 & 7.8 & 9.2 & 13.8 \\
\hline Average SST $(\mathrm{m} / \mathrm{s})$ & 26.1 & 25.9 & 25.9 & 26.1 & 26.0 \\
\hline Average AT $\left({ }^{\circ} \mathrm{C}\right)$ & 25.7 & 25.8 & 26.0 & 25.4 & 23.8 \\
\hline $\begin{array}{l}\text { Average air-sea temperature } \\
\text { difference }\left({ }^{\circ} \mathrm{C}\right)\end{array}$ & 0.4 & 0.1 & -0.1 & 0.7 & 2.2 \\
\hline Percentage among total samples (\%) & 43 & 57 & 73.3 & 23.6 & 2.1 \\
\hline
\end{tabular}

[2, 21]. The shape and height of waves directly determine the roughness of the ocean surface. In turn, the wave also influences air-sea fluxes like heat, momentum, and mass fluxes. In order to reveal temperature difference of air-sea and stratification of the MBL, the wave shapes first need to be categorized. By referring to Wang and Chang [20], the wave shapes can be categorized in accordance with the following three conditions:

$$
\begin{gathered}
\frac{U^{2}}{H} \leq 62.0, \\
\delta \leq 0.0177, \\
\beta \geq 1.07 .
\end{gathered}
$$

For formulas (6), $U$ is the wind speed, $H$ is the wave height, $\delta$ is the wave steepness (height-length ratio), and $\beta$ is the wave age. Wave is considered to be a swell wave if it satisfies at least two of the formulas; otherwise it is considered a wind wave. The waves in the Bohai Gulf during the experiment period were categorized according to the method. The statistical results for wind speed, AT, SST, and atmospheric stability (with different wave types) are listed in Table 2. Here, we can see that the average wind speed was $3.6 \mathrm{~m} / \mathrm{s}$ under the condition of wind waves, with the maximum of $13.8 \mathrm{~m} / \mathrm{s}$. Meanwhile, for swell waves, the mean wind speed was $1.5 \mathrm{~m} / \mathrm{s}$ with the maximum of only $4.1 \mathrm{~m} / \mathrm{s}$. By considering the distinct determining factors for wind and swell waves, the latter were formed outside of windy areas, generally with light and gentle winds. The differences between the average and minimum wind speeds for wind and swell waves indicated that the wave types were reasonably categorized according to the method presented earlier.

Data for the wave features was recorded every $20 \mathrm{~s}$. After calculating over $60 \mathrm{~min}$ average and data quality control, there were 195 sets of records. In accordance with the categorization method mentioned earlier, there were 82 sets of wind waves and their ratio was $43 \%$, and swell waves accounted for $57 \%$. For the wind waves, the SST was higher than the AT by the average of $0.4^{\circ} \mathrm{C}$. Here, unstable stratification appeared more $(52 \%)$. For the swell waves, the SST was higher than the AT by just $0.1^{\circ} \mathrm{C}$, and unstable stratification accounted for $78 \%$.

Furthermore, the features of SST, AT, and atmospheric stratification were analyzed according to wave height. On the basis of the standard of wave height categorization provided by the State Oceanic Administration, the Level2 wave height is between 0.1 and $0.4 \mathrm{~m}$, Level- 3 between 0.5 and $1.2 \mathrm{~m}$, and Level-4 between 1.3 and $2.4 \mathrm{~m}$. During the experiment period, the wave heights in the Bohai Gulf were generally less than $2.2 \mathrm{~m}$. Statistics indicated that there were 143 samples of Level-2 waves, accounting for $73.3 \%$, 46 Level-3 waves for $23.6 \%$, and 6 Level- 4 waves for only $2.1 \%$. Since the low number of Level- 4 wave samples limited their statistical reliability, they were omitted in the following analysis. The average AT during Level-2 waves was $26.0^{\circ} \mathrm{C}$, and unstable conditions amounted to $72 \%$. For Level- 3 waves, the average AT was $25.4^{\circ} \mathrm{C}$ (less than during the Level-2 waves). However, the mean value of SST minus AT was larger, and it reached $0.7^{\circ} \mathrm{C}$. Here, the probability of unstable stratifications decreased to $56 \%$. Therefore, we can conclude that wave height is positively correlated with wind speed as to the observation period, and that strong winds lead to AT reducing while not the same as SST. Therefore, the value of SST minus AT increased with wind speed. The variation of AT and SST with wind speed effectively demonstrates the air-sea interaction.

3.6. Wave-Coherent Momentum Flux. The air-sea fluxes exchange is one of the primary relationships in air-sea interaction. The momentum flux is closely related to current and wave features. It is also related to wind strength. For instance, during the strong convection process on August 15 th, the momentum flux increased significantly in relation to the temporarily strengthened surface winds. However, the correlation coefficient of the wind speed and momentum flux was 0.37 and far less than that of the South China Sea [12].

Based on the definition of momentum flux as (3), the momentum flux is proportional to the square of friction velocity, but not with wind speed. The wind speed can determine the intensity of waves. Therefore, the wave height is directly related to wind speed and results in the variations of sea surface roughness as well as friction velocity. The air-sea fluxes as momentum and heat fluxes (grouped by wave type and wave level) are listed in Table 3. The Level-2, Level-3, and Level- 4 waves correspond to average wind speeds of 1.8, 3.0, and $9.6 \mathrm{~m} / \mathrm{s}$, maximum wind speeds of $7.8,9.2$, and $13.8 \mathrm{~m} / \mathrm{s}$, and friction velocities of $0.29,0.4$, and $0.59 \mathrm{~m} / \mathrm{s}$, respectively. The friction velocity above the sea surface and momentum 
TABLE 3: Wave-coherent momentum flux and heat fluxes.

\begin{tabular}{|c|c|c|c|c|}
\hline \multirow[b]{2}{*}{ Category } & \multicolumn{2}{|c|}{ Grouped by wave shape } & \multicolumn{2}{|c|}{ Grouped by wave level } \\
\hline & Wind wave & Swell wave & $\begin{array}{c}\text { Level-2 } \\
(0.1-0.4 \mathrm{~m})\end{array}$ & $\begin{array}{c}\text { Level-3 } \\
(0.5-1.2 \mathrm{~m})\end{array}$ \\
\hline Average momentum flux $\left(\mathrm{W} / \mathrm{m}^{2}\right)$ & 0.2 & 0.1 & 0.1 & 0.2 \\
\hline Friction velocity $(\mathrm{m} / \mathrm{s})$ & 0.4 & 0.3 & 0.3 & 0.4 \\
\hline Average sensible heat flux $\left(\mathrm{W} / \mathrm{m}^{2}\right)$ & 19.7 & 29.0 & 28.2 & 13.9 \\
\hline Average latent heat flux $\left(\mathrm{W} / \mathrm{m}^{2}\right)$ & 26.3 & 37.1 & 30.6 & 42.2 \\
\hline
\end{tabular}

fluxes increased with wave height, with values of $0.14,0.23$, and $0.45 \mathrm{~W} / \mathrm{m}^{2}$, respectively. However, they were not linearly related to wind speed. Therefore, it is not appropriate to the linear dependence of momentum flux on wind speed in the Bohai Gulf. The wind speed may roughly represent the strength of momentum exchange; however, stratification, wave features (height, steepness, and age), breaking, and current speed can also lead to variations in the friction velocity at the ocean surface [22]. So, we can conclude that the air-sea momentum flux is synthetically affected by many factors.

In addition, Table 3 shows that wind speed effectively influenced both wave shape and wave height. With the wind increasing, wind waves developed. The stronger the wind becomes, the higher the waves, and the greater the friction velocity in the range of observation data. The mean momentum flux for wind waves was $0.21 \mathrm{~W} / \mathrm{m}^{2}$ and $0.14 \mathrm{~W} / \mathrm{m}^{2}$ for swell waves. The mean friction velocity for wind waves was $0.38 \mathrm{~m} / \mathrm{s}$, and $0.29 \mathrm{~m} / \mathrm{s}$ for swell waves. It indicated a stronger momentum exchange under the former conditions.

3.7. Wave-Coherent Heat Fluxes. Heat fluxes over ocean surface are in related to difference of air-sea temperature, lowatmosphere stability, humidity, wind speed, and whitecap. The diurnal variation magnitudes of AT and humidity over the sea are lower than over the land. Therefore, the heat fluxes are also comparatively lower. During the experiment period, the mean sensible heat flux was $21.6 \mathrm{~W} / \mathrm{m}^{2}$, and the median value was $5.9 \mathrm{~W} / \mathrm{m}^{2}$. It peaked in the afternoon, and decreased rapidly to nearly zero afterwards. The mean latent heat flux was $27.8 \mathrm{~W} / \mathrm{m}^{2}$, with a median of $21.8 \mathrm{~W} / \mathrm{m}^{2}$. In the daytime, the latent heat flux increased, while at night it decreased and approached zero without a notable peak. From August 6th to August 10th (with the influence of cold inflow from the northern area) the difference of air-sea temperature increased, and so did the sensible heat flux. The variations of latent heat flux and relative humidity showed an apparent anti-phase. The latent heat flux was lower during high humidity. The opposite was true during low humidity. For example, from August 10th to August 13th, northern winds prevailed in relation to the invasion of cold airflow. Here, the AT decreased with the lower humidity from $90 \%$ to $50 \%$, and the latent heat flux was greater during this period than on other days. Overall, the ratio of sensible and latent heat flux was 1.3 during the experiment period. It indicated their comparable importance for the air-sea exchange of heat. And there was distinct from the dominant position of latent

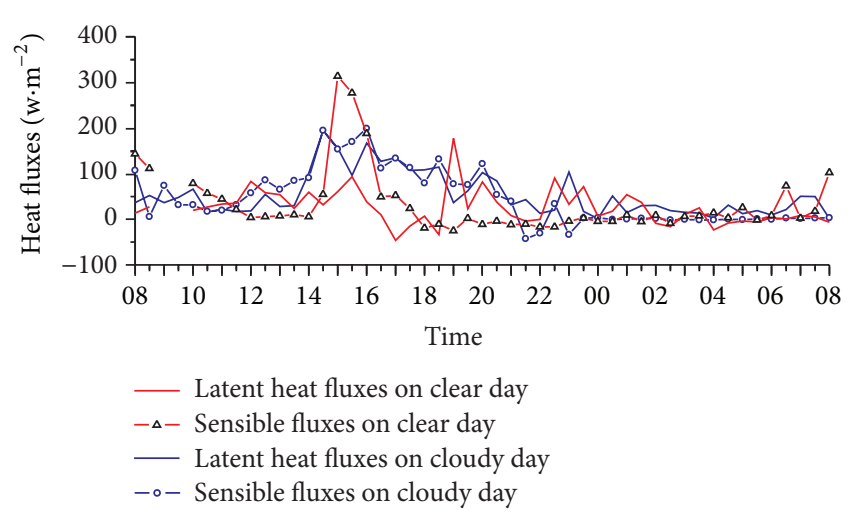

FIgURE 6: Diurnal variations in sensible and latent heat fluxes on clear and cloudy days.

heat flux found in the southern tropical sea area (the mean ratio of sensible and latent heat flux was 79 in July) [23]. In terms of diurnal variation, the magnitude of sensible heat flux was larger than that of the latent heat flux. However, the average daily latent heat flux was generally greater here than that of sensible heat flux in the location.

On clear and cloudy days (Figure 6), the heat fluxes were higher during the daytime afternoon and lower during the nighttime and early morning. The maximum sensible flux was greater on clear days than on cloudy days, with a sub-peak around 0600-0800 BJT. The mean sensible heat fluxes on clear and cloudy days were $44.8 \mathrm{~W} / \mathrm{m}^{2}$ and $24.7 \mathrm{~W} / \mathrm{m}^{2}$, respectively. The differentiation was due to Air-sea temperature difference under the condition of sunny and cloudy However, the average daily latent heat fluxes were similar under two kinds of weather conditions, $36.5 \mathrm{~W} / \mathrm{m}^{2}$ and $35.6 \mathrm{~W} / \mathrm{m}^{2}$, respectively. It was because latent heat fluxes are generally related to variations in air humidity.

\section{Discussion and Conclusions}

The paper used observational data collected during the composite observation experiment from early-mid August, 2011. Combining with conventional observations, meteorological and hydrological characteristics and their related air-sea fluxes were analyzed. Meanwhile, the limitation of the air-sea temperature difference for determining atmospheric stability was presented. The main conclusions are as follows.

(1) During early-mid August over the Bohai Gulf, southeaster predominates, followed by the northeaster. The winds 
are light to gentle breeze. The relative humidity was maintained above $60 \%$ without any significant diurnal variations. The AT was $26.2^{\circ} \mathrm{C}$ on average and had unimodal diurnal curve. It was determined by the amount of cloud cover, precipitation, cold airflows, and so forth. The SST was $25.9^{\circ} \mathrm{C}$ on average, and its daily variation was M-type. The variation of SST was mainly influenced by the tides with the minimum SST corresponding to the high water level during the observation period.

(2) The wave height was positively related to the wind speed. During the experiment, the proportion of Level-2 waves was $73.3 \%$ and Level-3 waves $23.6 \%$. Meanwhile, Level4 waves account only for $2.1 \%$. The mean wind speed during wind waves was $3.6 \mathrm{~m} / \mathrm{s}$ and $1.5 \mathrm{~m} / \mathrm{s}$ for swell waves. The swell waves appeared more frequently than the wind waves.

(3) The stability of the MBL over the Bohai Gulf was generally unstable, accounting for $70.2 \%$ overall in the background of the summer monsoon during early-mid August. Meanwhile, stability was related to wave shape and height. In the presence of wind waves, unstable stratification accounted for $52 \%$, and for swell waves the proportion was $78 \%$.

(4) Air-sea exchange was strengthened with the wind speed increasing. The mean surface momentum flux was $0.21 \mathrm{~W} / \mathrm{m}^{2}$ with the friction velocity of $0.38 \mathrm{~m} / \mathrm{s}$ for wind waves and greater than that for swell waves.

(5) When compared to the momentum flux, the diurnal variations of heat fluxes were weaker. The sensible heat was transported from the sea surface into the air with the average of $21.6 \mathrm{~W} / \mathrm{m}^{2}$ during the daytime and decreased to nearly zero during the night and affected greatly by insolation and cold advection. In addition, the latent heat flux was $27.8 \mathrm{~W} / \mathrm{m}^{2}$ on average and affected greatly by relative humidity. The ratio of latent heat to sensible heat flux was average 1.3, far lower than that found in the South China Sea.

Finally, it should be noted that the results presented were based on wind speeds mostly less than $8 \mathrm{~m} / \mathrm{s}$ (accounted for $97.6 \%$ ), so air-sea fluxes in the paper may be only limited to the condition of light to gentle breeze. And being a semienclosed inland sea, the Bohai Sea has complex terrain, and our results about meteorological and hydrological characteristics only represented an in situ sea area in the Bohai Gulf. Whether or not the results can be extended to the whole Bohai Sea area, more investigations were needed.

\section{Acknowledgments}

This work was supported by the financial support of the Meteorological Research Project of China (GYHY201006034; GYHY201106006), the National Natural Science Foundation of China (41075004), Natural Science Foundation of Tianjin (13JCYBJC20000), Science and Technology Xinghai Project of Tianjin (KJXH2012-25).

\section{References}

[1] I. Rivin and E. Tziperman, "Sensitivity of air-sea fluxes to SST perturbations," Journal of Climate, vol. 10, no. 10, pp. 2431-2446, 1997.
[2] J. B. Edson, A. A. Hinton, K. E. Prada, J. E. Hare, and C. W. Fairall, "Direct covariance flux estimates from mobile platforms at sea," Journal of Atmospheric and Oceanic Technology, vol. 15, no. 2, pp. 547-562, 1998.

[3] B. Liu, C. L. Guan, and L. A. Xie, "The wave state and sea spray related parameterization of wind stress applicable from low to extreme winds," Journal of Geophysical Research, vol. 117, pp. 110, 2012.

[4] E. C. Monahan and I. O. Muircheartaigh, "Optimal power-law description of oceanic whitecap coverage dependence on wind speed," Journal of Physical Oceanography, vol. 10, no. 12, pp. 2094-2099, 1980.

[5] E. C. Monahan, C. W. Fairall, K. L. Davidson, and P. J. Boyle, "Observed inter-relations between $10 \mathrm{~m}$ winds, ocean whitecaps and marine aerosols," Quarterly Journal of the Royal Meteorological Society, vol. 109, no. 460, pp. 379-392, 1983.

[6] M. A. Donelan, F. W. Dobson, S. D. Smith, and R. J. Anderson, "On the dependence of sea surface roughness on wave development," Journal of Physical Oceanography, vol. 23, no. 9, pp. 2143-2149, 1993.

[7] J. Liu, T. Xiao, and L. Chen, "Intercomparisons of air-sea heat fluxes over the Southern Ocean," Journal of Climate, vol. 24, no. 4, pp. 1198-1211, 2011.

[8] C. W. Fairall, E. F. Bradley, J. E. Hare, A. A. Grachev, and J. B. Edson, "Bulk parameterization of air-sea fluxes: updates and verification for the COARE algorithm," Journal of Climate, vol. 16 , no. 4, pp. 571-591, 2003.

[9] B. Sun, L. Yu, and R. A. Weller, "Comparisons of surface meteorology and turbulent heat fluxes over the Atlantic: NWP model analyses versus moored buoy observations," Journal of Climate, vol. 16, no. 4, pp. 679-695, 2003.

[10] K. Sopkin, C. Mizak, S. Gilbert, V. Subramanian, M. Luther, and N. Poor, "Modeling air/sea flux parameters in a coastal area: a comparative study of results from the TOGA COARE model and the NOAA Buoy model," Atmospheric Environment, vol. 41, no. 20, pp. 4291-4303, 2007.

[11] J. T. Chuj, J. N. Chen, and L. Y. Xu, "Improved calculation of turbulent heat fluxes at air-sea interface in maritime China," Oceanologia et Limnologia Sinica, vol. 37, no. 6, pp. 481-487, 2006.

[12] J. Yan, H. Yao, J. Li et al., "Air-sea heat flux exchange over the South China Sea under different weather conditions before and after southwest monsoon onset in 2000," Acta Oceanologica Sinica, vol. 22, no. 3, pp. 369-383, 2003.

[13] D. Vickers and L. Mahrt, "Sea-surface roughness lengths in the midlatitude coastal zone," Quarterly Journal of the Royal Meteorological Society, vol. 136, no. 649, pp. 1089-1093, 2010.

[14] F. Anctil, M. A. Donelan, W. M. Drennan, and H. C. Graber, "Eddy-correlation measurements of air-sea fluxes from a discus buoy," Journal of Atmospheric \& Oceanic Technology, vol. 11, no. 4, pp. 1144-1150, 1994.

[15] H. Liu, G. Peters, and T. Foken, "New equations for sonic temperature variance and buoyancy heat flux with an omnidirectional sonic anemometer," Boundary-Layer Meteorology, vol. 100, no. 3, pp. 459-468, 2001.

[16] M. Matthias and F. Thomas, Documentation and Instruction Manual of the Eddy Covariance Software Package Tk2, Universität Bayreuth, Abteilung Mikrometeorologie, 2004.

[17] M. Y. Tang, Y. Z. Liu, H. H. Li et al., "Seasonal variation characteristics of average surface sea temperature and its causes in the Bohai gulf, yellow sea and the north of the East China Sea," Acta Oceanologica Sinica, vol. 11, no. 5, pp. 544-553, 1989. 
[18] M. Årthun and C. Schrum, "Ocean surface heat flux variability in the Barents Sea," Journal of Marine Systems, vol. 83, no. 1-2, pp. 88-98, 2010.

[19] E. L. Andreas, "A relationship between the aerodynamic and physical roughness of winter sea ice," Quarterly Journal of the Royal Meteorological Society, vol. 137, no. 659, pp. 1581-1588, 2011.

[20] B. X. Wang and R. F. Chang, "Criteria of differentiating swell from wind waves," Journal of Oceanography of Huang Hai \& Bohai Gulfs, vol. 8, no. 1, pp. 16-24, 1990.

[21] A. Semedo, Ø. Saetra, A. Rutgersson, K. K. Kahma, and H. Pettersson, "Wave-induced wind in the marine boundary layer," Journal of the Atmospheric Sciences, vol. 66, no. 8, pp. 2256-2271, 2009.

[22] M. A. Donelan, B. K. Haus, N. Reul et al., "On the limiting aerodynamic roughness of the ocean in very strong winds," Geophysical Research Letters, vol. 31, no. 18, pp. 1-5, 2004.

[23] Q. Z. Sun, J. N. Cheng, J. Y. Yan et al., "The variation characteristics of air-sea fluxes over the Xi'sha area before and after the onset of the South China Sea monsoon in 2008," Acta Oceanologica Sinica, vol. 32, no. 4, pp. 12-23, 2010. 

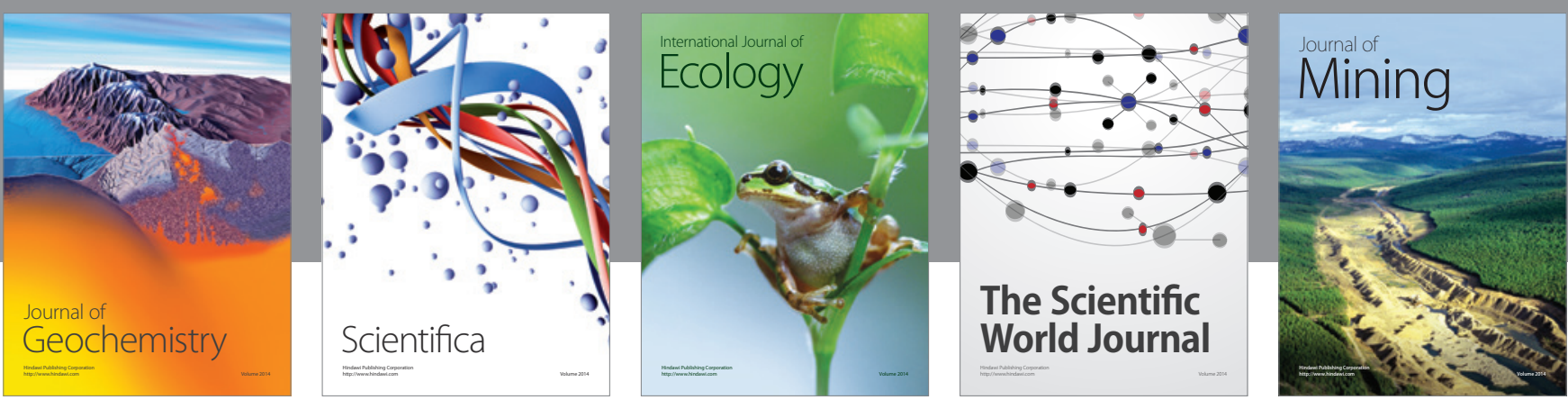

The Scientific World Journal
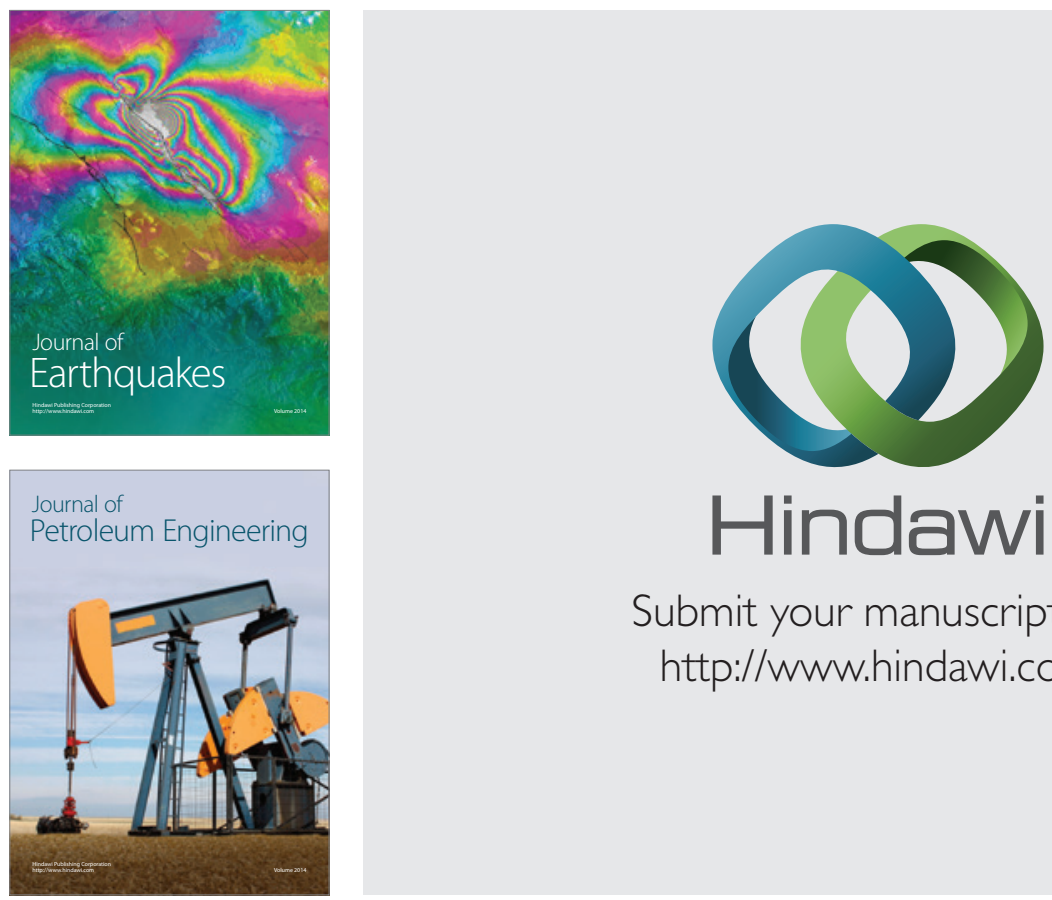

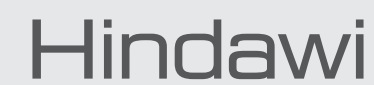

Submit your manuscripts at

http://www.hindawi.com
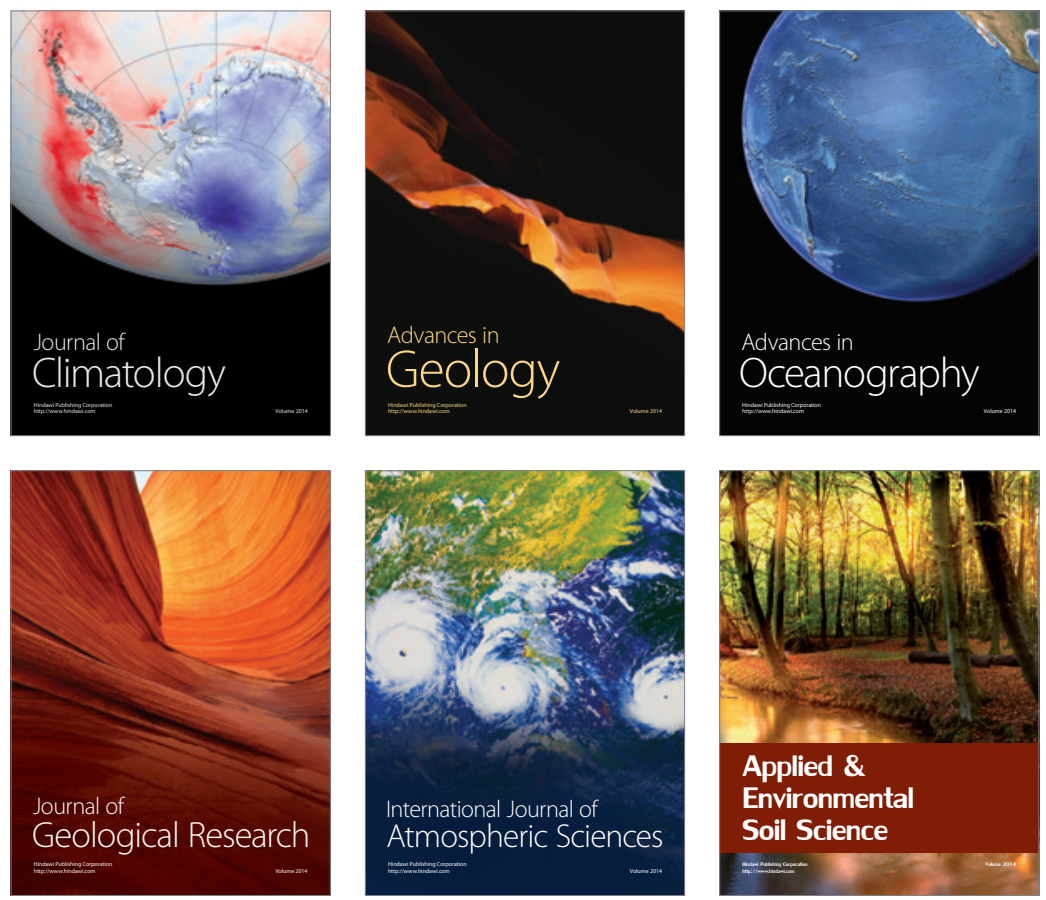
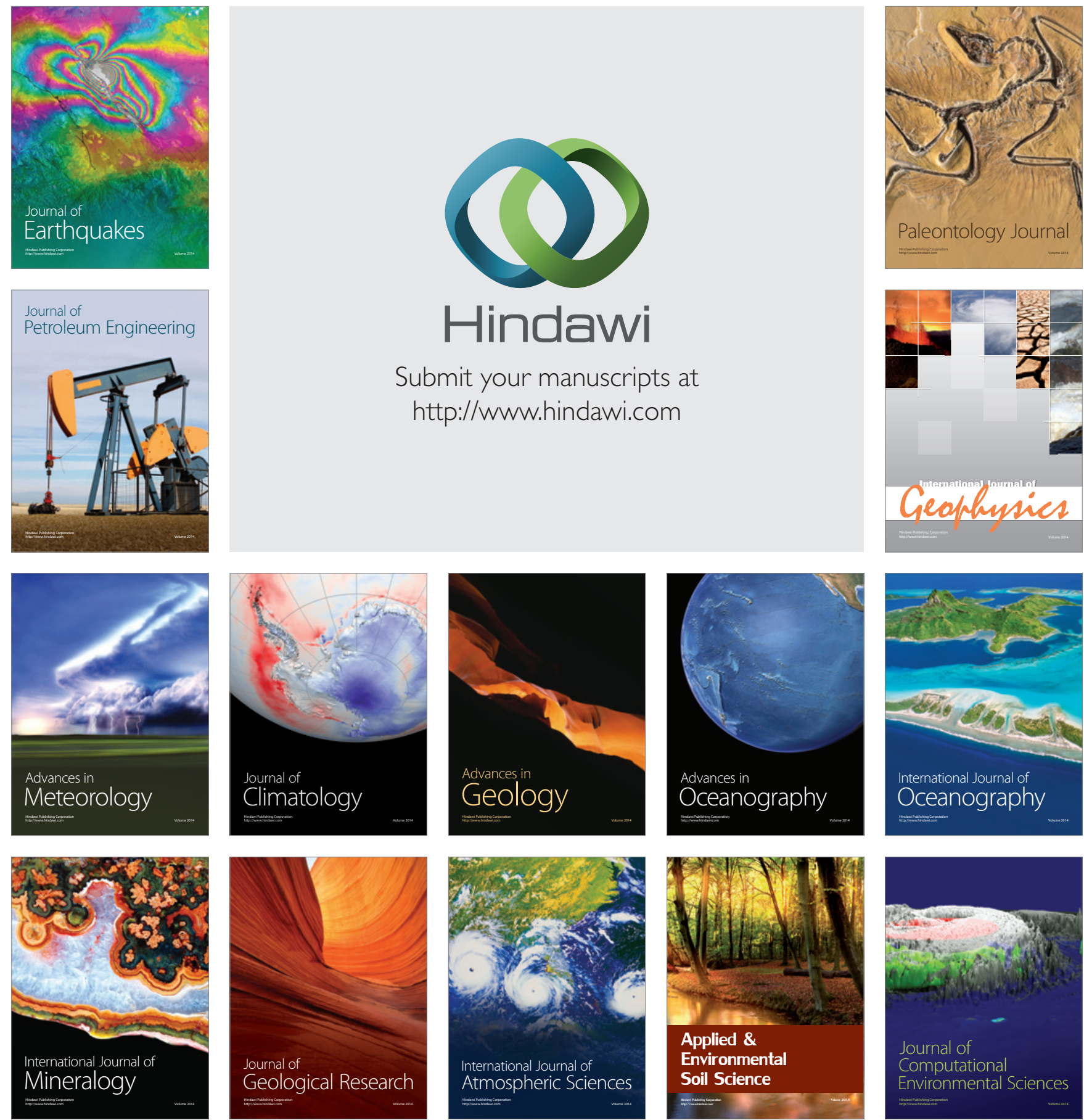